\title{
Impaired colour discrimination among workers exposed to styrene: relevance of a urinary metabolite
}

Teruko Eguchi, Reiko Kishi, Izumi Harabuchi, Junko Yuasa, Yoshihiko Arata, Yohko Katakura, Hirotsugu Miyake

\begin{abstract}
Objectives-To survey the loss of colour vision among Japanese workers who have been exposed to styrene concentrations currently considered low (about 20 ppm). Also to assess the effects of styrene by examination of the nature of the relation between disorder of colour vision and age, alcohol consumption, and other variables.
\end{abstract}

Methods-Colour discrimination was examined in 64 male workers exposed to styrene (mean age; $38 \cdot 0$, mean exposed years; 7.0) and in 69 controls (mean age; 38.0). A standardised questionnaire was adopted to collect work history, occupational or non-occupational solvent exposure, alcohol consumption, and drug use. Colour vision was evaluated by the Lanthony desaturated panel D-15 test. The results of the test were expressed as the colour confusion index (CCI).

Results-The mean atmospheric styrene concentration was about $20 \mathrm{ppm}$. The mean urinary concentration of mandelic acid was $0.22 \mathrm{~g} / 1$. There was a significant difference in CCI between exposed workers and age matched controls. Colour vision of workers whose concentration of urinary mandelic acid was $\geqslant 0.42$ g/l was significantly impaired when compared with workers whose concentration was $<0.42 \mathrm{~g} /$. Multiple linear regression analysis that controlled confounding variables such as age, alcohol consumption, smoking, and educational attainment showed that the CCI was significantly related to the concentration of urinary mandelic acid. In both exposed workers and controls, the types of defects were mostly blue-yellow loss, although a few subjects showed complex loss. No one showed only red-green loss.

Conclusions-These findings suggest that exposure to moderate styrene concentrations can lead to impairment of colour vision, and that there is a significant correlation with the urinary metabolite of styrene.

\section{(Occup Environ Med 1995;52:534-538)}

Keywords: styrene; colour vision; urinary mandelic acid

Acquired defects in colour vision are caused by a variety of diseases that damage the retina, the optic nerve, or the visual cortex. Toxic, vascular, inflammatory, and neoplastic diseases are all well-recognised causes of acquired dyschromatopsia. ${ }^{1}$ Compared with congenital dyschromatopsia, acquired dyschromatopsia is more complex. ${ }^{2}$ It is always a pathological condition, which involves senile changes. It is unstable, progressively deteriorating, or occasionally improving if the underlying pathological conditions are reversible. The axes are not always definite and there are variations between eyes.

Acquired loss of colour vision has been associated with exposure to organic solvents present in the workplace, ${ }^{3-7}$ which raises interest in the use of tests designed to assess neurotoxic effects of solvent exposure. As one of the organic solvents, styrene has been used in the manufacture of plastics and has a wide variety of industrial applications. Chronic styrene exposure affects the central and peripheral nervous systems, ${ }^{8}$ and some cases of retrobulbar neuritis because of heavy occupational exposure have been reported. ${ }^{9}$ Recently there have been a few studies of impairment of colour vision of workers exposed to styrene. ${ }^{1011}$

In our study we surveyed the loss of colour vision among Japanese workers who were exposed to styrene concentrations currently considered to be low (about $20 \mathrm{ppm}$ ). We also assessed the effects of styrene by examining the nature of the relation between the disorder of colour vision and age, alcohol consumption, ${ }^{12}$ and other variables that might influence the occurrence of loss of colour vision.

\section{Methods}

SUBJECTS

Sixty nine workers exposed to styrene (64 men and five women) were studied from six fibreglass and reinforced plastics factories. The factories made bathtubs, parts of unit baths, septic tanks, etc. Styrene was by far the most used solvent. Acetone was used to clean tools. The control group consisted of 84 workers (69 men and 15 women) from the same and other factories. None of them were exposed to styrene or other industrial solvents. All subjects gave their informed written consent to the protocol. A standardised questionnaire was adopted to collect work history, occupational or non-occupational solvent exposure, alcohol consumption, and drug use. The following criteria for exclusion from the study were adopted: (a) presence of congenital dyschromatopsia, (b) presence of hypertension, (c) use of drugs that interfere with 
Figure 1 Distribution of urinary mandelic acid in the workers exposed to styrene.

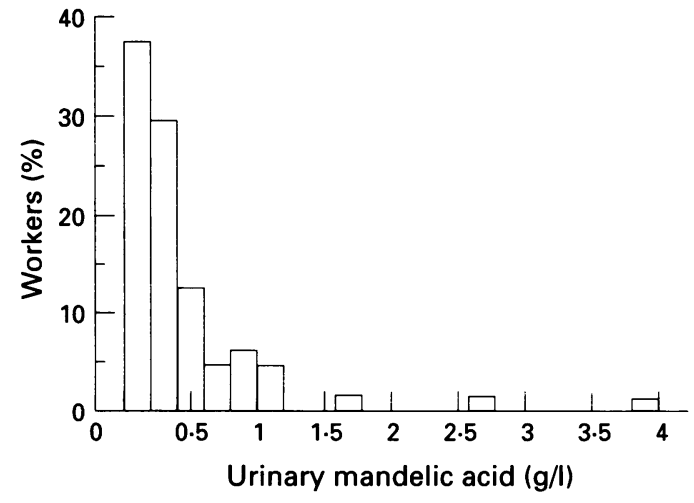

colour vision, $(d)$ visual acuity lower than $6 / 10$ in either eye, and $(e)$ alcohol consumption over $250 \mathrm{~g} /$ week. $^{10}$

Because of the small sample size, female workers were excluded. Therefore 64 exposed workers and 69 controls were included in this study. The mean (range) age of exposed workers was 38.0 (18-66), the duration of exposure was $7 \cdot 0(0 \cdot 2-26 \cdot 8)$ years. The age of controls was $38 \cdot 0(20-61)$.

\section{EXPOSURE}

The mean (range) atmospheric styrene concentration (by area sampling, not personal sampling) was $18.5(6 \cdot 6-36 \cdot 4) \mathrm{ppm}$. Urine of all exposed workers was collected at the end of the shift on the day of the colour vision test. Subjects urinated and drank a glass of water two hours before collection of urine to ensure consistency among urine samples collected. The mandelic acid concentration was measured by high performance liquid chromatography. ${ }^{13}$ Mandelic acid concentrations were low: $56.3 \%$ of workers had $<0.3 \mathrm{~g} / 1,34.4 \%$ had $0.3-1.0 \mathrm{~g} / 1$, and only $9.4 \%$ had $>1.0 \mathrm{~g} / 1$ (fig 1). The mean (SD) urinary concentration of mandelic acid was $0.22 \mathrm{~g} / 1(0.48)$. Because the technology used in the fibreglass factories studied was similar for job tasks and work load, we considered all workers as a single group.

\section{COLOUR DISCRIMINATION ASSESSMENT}

Colour vision was assessed with the colour arrangement test-namely, the Lanthony desaturated panel D-15 test. ${ }^{14}$ Fifteen pastel caps, numbered on the back, were placed in front of the subject in random order. The subject was required to place the caps in an oblong box, in order of chromatic similarity, starting from a fixed reference cap. In most of the workers exposed to styrene, colour vision was tested on Monday, but some workers were tested on Tuesday. The test was performed at the beginning of the workday, before exposure, under a daylight fluorescent lamp that provided 1000 lux on the working plane. The test was carried out monocularly and no time limit was imposed. Most people completed the test in one to three minutes an eye. Subjects who wore glasses used them. Colour vision test performance was assessed categorically and quantitatively. Colour vision categories included: (a) normal colour vision (no errors, single sequential error or paired reversal), and (b) two or more errors (with subcategorisation according to the relative predominance of errors in red-green or blueyellow). ${ }^{15} \mathrm{~A}$ person was considered dyschromatopic if colour loss was identified in either eye. Quantitative evaluation was by calculation of the sum of the colour differences of the caps placed next to one another (total colour difference score; TCDS), with the formula proposed by Bowman. ${ }^{16}$ The colour confusion index (CCI) was obtained when the actual TCDS for a subject's test cap arrangement was divided by the TCDS for a perfect arrangement of that test. ${ }^{17}$ Therefore 1 indicated a perfect score and values $>1$ indicated increasing loss of colour vision. Data are presented as the mean CCI of both eyes of each worker.

\section{STATISTICAL METHODS}

Pearson's correlation coefficients were calculated to assess the association between CCI and age. Spearman's correlation coefficients were calculated to assess the association between CCI and urinary mandelic acid. Because the normal distribution of each variable could not be identified, comparisons of values between groups were assessed by the Mann-Whitney $U$ test and the Wilcoxon signed rank test. ${ }^{18}$ Multiple regression analysis was used to investigate the relation between exposure to styrene and CCI while controlling for potential confounding factors. ${ }^{19}$ The backward elimination technique was used, whereby all variables were entered into the equation, then sequentially removed if the probability of its $F$ value was $>0.05$. The suspected interaction between exposure duration and exposure level was also investigated in the regression models by including the product of the subject's exposed years and the mandelic acid concentration in urine. ${ }^{19}$ All independent variables were mutually uncorrelated (correlations were below 0.9). ${ }^{19}$ We used the arithmetic mean throughout.

\section{Results}

Significant linear correlations were present for age and TCDS in both workers exposed to styrene (TCDS $=54.14+0.46 \times$ age; $r=$ $0.39 ; \mathrm{P}<0.01$ ) and controls (TCDS $=52.53$ $+0.34 \times$ age; $r=0.48 ; \mathrm{P}<0.01$, fig 2$)$. The control line was similar to that of Bowman et al $(\text { TCDS }=49.4+0.37 \times \text { age })^{17}$ and Gobba et al $\left(\right.$ TCDS $=55.89+0.37 \times$ age).$^{10}$

To exclude the influence of age, we matched the two groups according to age (within three years). We thus obtained a total of 57 age matched pairs. The mean (SD) CCI of exposed workers was $1.220(0 \cdot 235)$, age was $37 \cdot 8(11 \cdot 5)$, whereas the CCI of controls was $1 \cdot 120(0 \cdot 128)$, and age was $37 \cdot 8(11 \cdot 0)$. There was a significant difference for CCI between exposed workers and controls (Wilcoxon signed rank test, $P<0.01$ ). To explore the possibility of a dose-effect relation between styrene exposure and loss of colour vision we divided the exposed workers into 


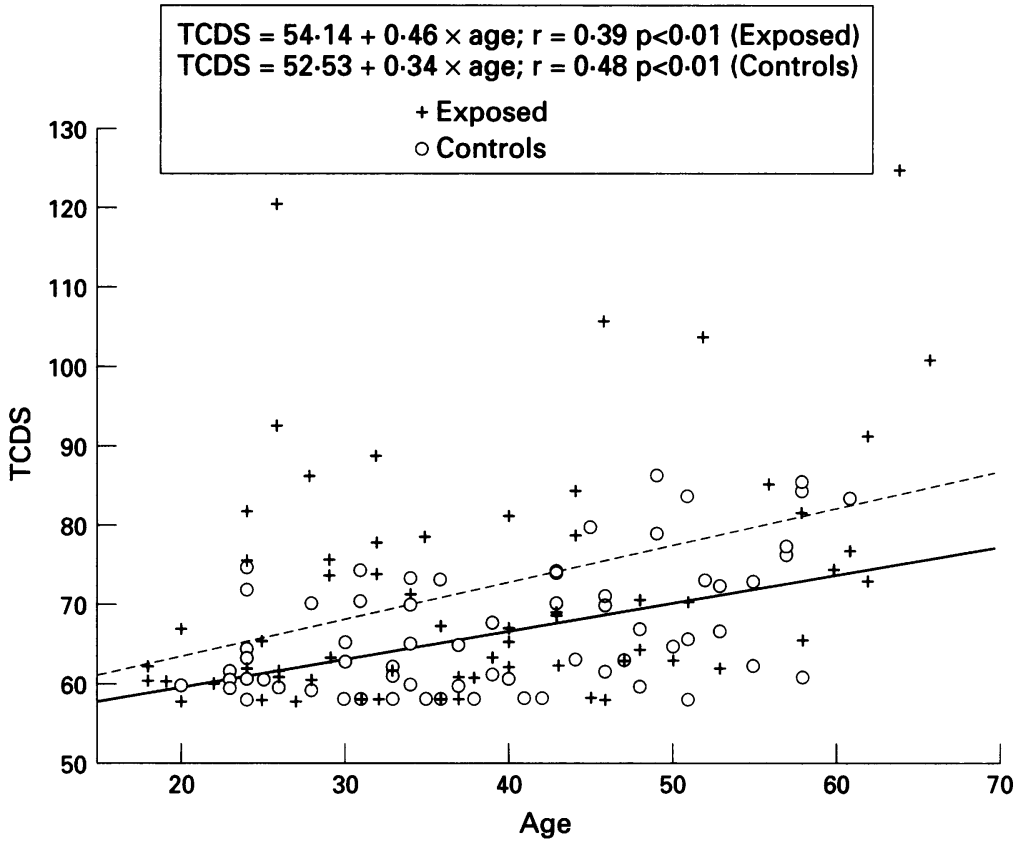

Figure 2 Relations between the total colour difference score (TCDS) and age in the workers exposed to styrene and in controls. styrene concentration of about $93 \mathrm{ppm}$. Then each subgroup was compared with age matched controls. There was a significant difference in subgroup B but not in subgroup A (Wilcoxon signed rank test)-that is, the $P$ values were $<0.01$ and 0.12 , respectively. A significant difference in CCI was found between exposed workers of subgroup $A$ and those of subgroup B (table 1).

In each subgroup, a scattergram was plotted between CCI and urinary mandelic acid (fig 3). Although significant correlations were not found, Spearman's correlation coefficients were -0.24 in subgroup $A$ and 0.32 in subgroup $B$-that is, the $P$ values were 0.12 and $0 \cdot 18$, respectively.

Results of the stepwise regression analysis showed that CCI had a significant positive relation to urinary mandelic acid after control for age. Duration of exposure did not have a significant relation with CCI. Alcohol consumption did not have any relation to $\mathrm{CCI}$, but smoking was negatively related to CCI. A significant interaction between duration of exposure and the urinary concentration of mandelic acid was not found (table 2).

In both exposed workers and controls, the types of defects were mostly blue-yellow loss, although a few subjects showed complex loss. No one showed only red-green loss. nary concentration of mandelic acid was $<$ or $\geqslant 0.42 \mathrm{~g} / \mathrm{l}$, which was equivalent to an atmospheric styrene concentration of about 30 $\mathrm{ppm}^{20}$ (subgroup A: $<0.42 \mathrm{~g} /$, subgroup $\mathrm{B}$ : $\geqslant 0.42 \mathrm{~g} / \mathrm{l}$ ). The mean (range) urinary concentration of mandelic acid of subgroup A was $0.20(0.04-0.41) \mathrm{g} / \mathrm{l}$ and it was equivalent to an atmospheric styrene concentration of about $8 \mathrm{ppm}$. That of subgroup B was 1.06 $(0.46-3.98) \mathrm{g} / \mathrm{l}$, equivalent to an atmospheric

\section{Discussion} associated with age, ${ }^{217} 2122$ we first excluded the effect of age. The CCI values of exposed workers were significantly higher than those of the age matched controls.
Figure 3 Relations between the colour confusion index (CCI) of exposed workers and urinary mandelic acids in subgroups $A$ and $B$.
Table 1 Age matched comparison of workers exposed to styrene and controls (57 pairs) stratified by urinary mandelic acid concentration

\begin{tabular}{|c|c|c|c|c|}
\hline & \multicolumn{2}{|c|}{ Subgroup $A$ (mandelic acid $<0.42 \mathrm{~g} /$ l) } & \multicolumn{2}{|c|}{ Subgroup $B$ (mandelic acid $\geqslant 0.42 \mathrm{~g} / \mathrm{l}$ ) } \\
\hline & $\begin{array}{l}\text { Workers exposed } \\
\text { to styrene } \\
(n=40)\end{array}$ & $\begin{array}{l}\text { Age matched } \\
\text { controls } \\
(n=40)\end{array}$ & $\begin{array}{l}\text { Workers exposed } \\
\text { to styrene } \\
(n=17)\end{array}$ & $\begin{array}{l}\text { Age matched } \\
\text { controls } \\
(n=17)\end{array}$ \\
\hline \multirow{3}{*}{$\begin{array}{l}\text { Age } \\
\text { Urinary mandelic } \\
\text { acid }(g / 1) \\
\text { Exposure } \\
\text { duration }(y) \\
\text { CCI }\end{array}$} & $39.6(11.5) \dagger$ & $39.5(10.8) \ddagger$ & $33 \cdot 8(11 \cdot 0)$ & $33 \cdot 8(10 \cdot 7) \ddagger$ \\
\hline & $0.20(0.11)^{\star \star}$ & & $1.06(0.93)$ & \\
\hline & $\begin{array}{l}8 \cdot 2(8.0) \dagger \\
1.173(0.191)^{\star}\end{array}$ & $1 \cdot 118(130) \ddagger$ & $\begin{array}{l}5 \cdot 5(5 \cdot 6) \\
1.332(0 \cdot 292)\end{array}$ & $1.125(0.126) \mathrm{H}$ \\
\hline
\end{tabular}

$\star P<0.05 ; \star \star P<0.001 ;+N S ;$ differences between subgroup $A$ and subgroup $B$ in exposed workers; $\ddagger N S ;+P<0.01 ;$ differences between exposed workers and controls. Values are arithmetic mean (SD).

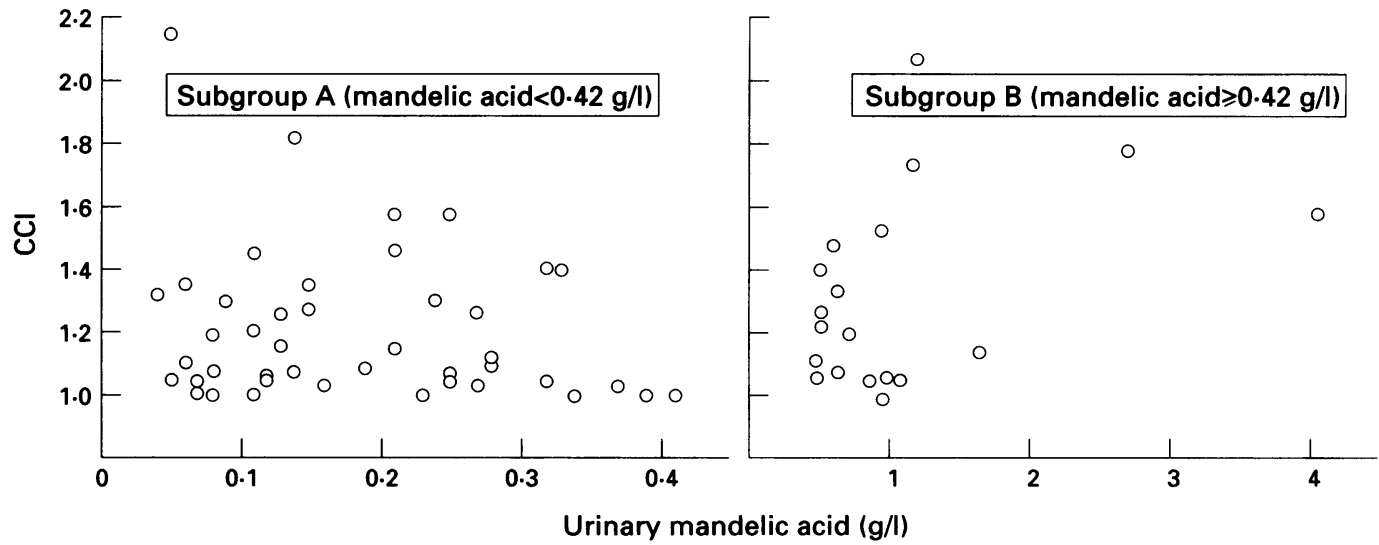


Table 2 Results of stepwise backward regression analysis; (64 workers exposed to styrene $(n=64))$

\begin{tabular}{lllll}
\hline & Coefficients & (SEM) & $\begin{array}{l}\text { Standardised } \\
\text { coefficients }\end{array}$ & P value \\
\hline 1 Intercept & 0.979 & $(0.091)$ & 0.979 & $<0.001$ \\
2 Age & 0.007 & $(0.002)$ & 0.353 & $<0.01$ \\
3 Amount of alcohol consumption (ml/week) & - & - & - & $\mathrm{NS}$ \\
4 Frequency of alcohol consumption & - & - & - & $\mathrm{NS}$ \\
4 Smoking & - & - & - & $\mathrm{NS}$ \\
5 Educational attainment & - & - & - & $\mathrm{NS}$ \\
6 Exposure duration & 0.160 & $(0.041)$ & 0.416 & $<0.01$ \\
7 Urinary mandelic acid level & - & - & - & $\mathrm{NS}$ \\
8 Exposure duration $\times$ urinary mandelic acid & - & & &
\end{tabular}

Adjusted $R^{2}=0 \cdot 328$. tice in Japanese laboratories, thus, we measured it as an indicator of the exposure. Also, as urinary mandelic acid excretion is a marker for actual body burden, it may not strongly relate to chronic or subchronic effects such as dyschromatopsia.

Secondly, multiple regressions gave an adjusted $R^{2}$ of about 0.3 , which implies that the factors identified were not very powerful as a whole. One explanation for this is that there are many other factors related to tests of colour vision such as lens or macular changes, work area lighting, ${ }^{15}$ subject motivation, etc, besides the variables entered in this model.

In most subjects, the blue-yellow range of colour vision was affected as in previous studies. ${ }^{1011}$ According to Köllner's rule, blueyellow defects appear in retinal disease and red-green defects in optic nerve disease. But not all cases of acquired dyschromatopsia conform neatly to Köllner's rule. ${ }^{21}$ It is difficult to guess the aetiology of defects of colour vision only from this test and some hypotheses have been considered based on other knowledge. Raitta et al reported that $n$-hexane caused macular changes and acquired defects of colour discrimination, and that $n$-hexane maculopathy might be a result of damage to receptor lipids. ${ }^{6}$ Schaumburg and Spencer found that $2 \cdot 5$-hexanedione, a metabolite of $n$-hexane, caused widespread axonal degeneration in the mammillary body, the lateral geniculate nucleus, and the superior colliculus of intoxicated cats. ${ }^{23}$ Mergler et al suspected that acquired dyschromatopsia related to mixed solvents reflects not ocular integrity but neural alterations. ${ }^{3}$ For mechanisms described above, loss of colour vision may be due to interference of styrene with the dopaminergic mechanism of retinal cells, ${ }^{10}$ as suggested for other neurotoxic effects. ${ }^{24}$

There are several methods to test colour vision, but not all of them are adequate to detect acquired defects. ${ }^{25}$ The FarnsworthMunsell 100-hue test is the one most widely used for detecting acquired defects. ${ }^{21}$ It provides a straightforward way of characterising defects of hue discrimination in patients with dyschromatopsia but is none the less a rather inconvenient and time consuming test. The Lanthony desaturated panel D-15 test ${ }^{14}$ is not suitable for precise classification of dyschromatopsia in comparison with the FarnsworthMunsell 100-hue test, but it is helpful to detect dyschromatopsia. ${ }^{26}$ It is non-invasive, rapid, portable, and easy to carry out. Therefore the Lanthony desaturated panel D15 test seems to be a relatively useful tool to assess loss of colour vision in field studies. If the colour vision of workers is checked before and after styrene exposure, early toxic influences on vision can be detected, and compared with the individual pre-exposure baseline of colour vision. ${ }^{27}$

We acknowledge the assistance provided by Dr Hiroshi We acknowledge the assistance provided by Dr Hiroshi
Yokoyama, Ms Keiko Tazawa, Ms Ayano Nagai, and memYokoyama, Ms Keiko Tazawa, Ms Ayano Nagai, and mem-
bers of the Hokkaido Labour Health Management Society for bers of the Hokkaido Labour Health Management Society for
performing the analysis of urinary mandelic acid. This study performing the analysis of urinary mandelic acid. This study was supported by a grant in aid from
Education, Science, and Culture. when subclinical effects were found in study. The use of mandelic acid concentrations without any correction is standard prac- 
1 Hart WM Jr. Color vision. In: Hart WM Jr, ed. Adler's physiology of the eye, 9th ed. St. Louis: Mosby-Year Book, 1992:708-27.

2 Lakowski R. Theory and practice of colour vision testing: a review part 1. Br F Ind Med 1969;26:173-89.

3 Mergler D, Blain L, Lagace JP. Solvent related colour vision loss: an indicator of neural damage? Int Arch Occup Environ Health 1987;59:313-21.

4 Mergler D, Belanger S, Grosbois S, Vachon N. Chromal focus of acquired chromatic discrimination loss and solvent exposure among printshop workers. Toxicology 1988;49:341-8.

5 Mergler D, Huel G, Bowler R, Frenette B, Cone J. Visual dysfunction among former microelectronics assembly workers. Arch Environ Health 1991;46:326--34

6 Raitta C, Seppalainen AM, Huuskonen MS. N-hexane maculopathy in industrial workers. Albrecht $v$ Graefes Arch Klin Exp Ophthal 1978;209:99-110.

7 Raitta C, Teir H, Tolonen M, Nurminen M, Helpio E, Malmstrom S. Impaired color discrimination among viscose rayon workers exposed to carbon disulfide. 7 Occup Med 1981;23:189-92.

8 Cherry N, Gautrin D. Neurotoxic effects of styrene: further evidence. $\mathrm{Br}$ F Ind $\mathrm{Med}$ 1990;47:29-37.

9 Grant WM. Toxicology of the eye, 3rd ed. Springfield, Ill: Charles C Thomas, 1986:854-5.

10 Gobba F, Galassi C, Imbriani M, Ghittori S, Candela S, Cavalleri A. Acquired dyschromatopsia among styreneexposed workers. F Occup Med 1991;33:761-5.

11 Fallas C, Fallas J, Maslard P, Dally S. Subclinical impairment of colour vision among workers exposed to styrene. Br F Ind Med 1992;49:679-82.

12 Mergler D, Blain L, Lemaire J, Lalande F. Colour vision impairment and alcohol consumption. Neurotoxicol Teratol 1988;10:255-60.

13 Ogata M, Taguchi T. Quantitation of urinary metabolites of toluene, xylene, styrene, ethylbenzene, benzene, and phenol by automated high performance liquid chromatography. Int Arch Occup Environ Health 1987;59: matography
14 Lanthony P. The desaturated panel D-15. Doc Ophthalmol 1978;46:185-9.

15 Baird B, Camp J, Daniell W, Antonelli J. Solvents and color discrimination ability. Nonreplication of previous findings. F Occup Med 1994;36:747-51.

16 Bowman KJ. A method for quantitative scoring of the Farnsworth Panel D-15. Acta Opthalmol 1982;60:90716.

17 Bowman KJ, Collins MJ, Henry CJ. The effects of age on performance on the Panel D-15 and Desaturated D-15: a quantitative evaluation. Documenta Ophthalmologia Proceedings Series 1984;39:227-31.

18 Siegel S, Fujimoto H, eds. Non-parametric statistics: for the behavioral science. Tokyo: McGraw-Hill Book Company, Japan, 1983.

19 Kleinbaum DG, Kupper LL, Muller KE. Applied regression analysis and other multivariate methods, 2nd ed. California: Duxbury Press, 198

20 Ikeda M, Koizumi A, Miyasaka M, Watanabe T. Styrene exposure and biologic monitoring in FRP boat production plants. Int Arch Occup Environ Health 1982;49: 325-39.

21 Hart WM Jr. Acquired dyschromatopsias. Surv Opthalmol 1987;32:10-31.

22 Verriest $G$. Further studies on acquired deficiency of color discrimination. F Opt Soc Am 1963;53:185-95.

23 Schaumburg HH, Spencer PS. Environmental hydrocarbons produce degeneration in cat hypothalamus and optic tract. Science 1978;199: 199-200.

24 Mutti A. Toxicity of metabolites to dopaminergic systems and the behavioural effects of organic solvents. Br F Ind Med 1987;44:721-3.

25 Lakowski $R$. Theory and practice of colour vision testing: a review. Part 2. Brf Ind Med 1969;26:265 88

26 Mergler D, Blain L. Assessing color vision loss among solvent-exposed workers. Am f Ind Med 1987;12:195-203.

27 Grant WM. The peripheral visual system as a target. In: Spencer P, Schaumburg H, ed. Experimental and clinical Spencer P, Schaumburg H, ed. Experimental and clinical
neurotoxicology. London: Williams and Wilkins, 1980: 77-91. 